\title{
Some evidence on additive learning models
}

\author{
A. E. DUSOIR \\ City of London Polytechnic, London E1 7NT, England
}

\begin{abstract}
Deterministic and probabilistic additive learning models for signal detection/recognition replace the fixed criterion of classical detection models with one which shifts from trial to trial in the light of the preceding trial events. Data from a sinusoid in noise detection task without feedback and an auditory amplitude recognition task with feedback are used to test these models with respect to their predictions about asymptotic response frequency, and, where possible, by likelihood ratio tests. These and some previous experiments show that whether or not feedback is given subjects do not universally probability match, overmatch, undermatch, or keep response probability constant over discriminability, so that none of the testable special models can fit more than a proportion of subjects. The likelihood ratio tests confirm this conclusion for the special deterministic models. The six-parameter general deterministic model does nonsignificantly better than an ad hoc six-parameter response runs model in fitting the recognition data and significantly better than the five-parameter memory recognition model of Tanner, Rauk, and Atkinson (1970). Monte Carlo methods are used to confirm the applicability of asymptotic response frequency results to practically feasible sample sizes.
\end{abstract}

In the classic detection/recognition task, stimuli $\mathrm{s}_{1}, \mathrm{~s}_{2}$ are presented in a Bernoulli sequence with probabilities $1-\gamma, \gamma$ and at each trial the subject responds $r_{1}$ or $r_{2}$, with $r_{i}$ correct for $s_{i}$. Early models assumed a r.r.v.X, with distribution $f_{i}(x)$ given $s_{i}$, and a fixed criterion $\mathrm{c}$ on $\mathrm{X}$ such that

$$
p\left(r_{2} \mid s_{i}\right)=\int_{c}^{\infty} f_{i}(x) d x
$$

such models predict zero sequential effects and binomial $p\left(r_{2} \mid s_{i}\right)$ variance against the facts. Additive learning models (ALMs) replace the fixed criterion with one which may shift from trial to trial in the light of the last trial events. Because the size of shift is assumed not to depend on the current criterion position, the models are additive.

Recently, the theory of ALMs has been considerably developed (Norman, 1972, 1974; Thomas, 1973, 1975). Theorems about the asymptotic behavior of the $r_{2}$ response frequency over $N$ trials, $p_{N}\left(r_{2}\right)$, as $\mathrm{N} \rightarrow \infty$ allow simple tests of many special cases of the models without any assumptions about the form of the $f_{i}(x)$ or about initial criterion position: for example, some of the models predict probability matching [ $\hat{\mathrm{p}}_{\mathrm{N}}\left(\mathrm{r}_{2}\right) \stackrel{\text { a.s. }}{\rightarrow} \gamma$ as $\mathrm{N} \rightarrow \infty$ ], or else departures from matching which are constant in size or direction as discriminability varies. Also, if the $f_{j}(x)$ are specified, maximum likelihood parameter estimates are often fairly readily obtained, so that likelihood ratio tests become possible. Nevertheless, the mod-

Address for reprint requests: School of Psychology, Ulster Polytechnic, Shore Road, Newtownabbey, County Antrim BT37 0QB, Northern Ireland. els have not so far been seriously tested in the literal detection/recognition context, apart from Dorfman, Saslow, and Simpson (1975); Kubovy and Healy (1977) apply them to a task involving externally distributed stimuli. This paper reports some new data, and also provides the first evidence on the validity of applying the asymptotic theory about $p_{N}\left(r_{2}\right)$ to the kind of $N$ that is practically feasible.

Note that though much of the paper concerns ALMs, the data on $\hat{p}_{N}\left(r_{2}\right)$ has a wider relevance, to the matching hypothesis of Thomas and Legge (1970) and the proposal that $p\left(r_{2}\right)$ is an adequate bias parameter (Dusoir, 1975).

\section{THE MODELS}

According to the models, the stimuli, $s_{1}$ and $s_{2}$, are represented internally by distributions $f_{1}(x)$ and $f_{2}(x)$ on a r.r.v.X. At trial $j$, the subject has a criterion $c_{j}$ and responds $r_{2}$ if $x>c_{j}, r_{1}$ otherwise. What characterizes ALMs specifically is the assumption that

$$
c_{n+1}=c_{n}+d_{e}, \quad \text { e } \varepsilon E
$$

where $e$ is an event in an event set $E$, and $\delta_{e}$ is a real number representing the criterion shift; or alternatively that

$$
C_{n+1}=c_{n}+\Delta_{e}, \quad \text { e } \varepsilon E
$$

where $\Delta_{\mathrm{e}}$ is a r.r.v.. Equation 1 characterizes deterministic ALMs, and Equation 2, probabilistic ALMs. In both types of model, given current criterion $c_{j}$, there exists a distribution function over $E$, so that the 
process $\left\{C_{n}, n=0,1, \ldots\right\}$ is Markovian. A special case of the first type of model was considered by Kac (1962), and the general theory was later developed by Dorfman and his co-workers (Dorfman, 1973; Dorfman \& Biderman, 1971; Dorfman, Saslow, \& Simpson, 1975) and Norman (1972). The probabilistic models were developed by Thomas $(1973,1975)$. The reader is referred to these original sources, especially Norman (1972), for a careful and rigorous statement of the models; here the limited aim is to summarize those aspects of the models which make them conveniently testable.

\section{Deterministic Models, $e=\left(s_{\mathbf{j}} \mathbf{r}_{\mathbf{j}}\right)_{\mathbf{n}}$}

All these deterministic models take $E$ to include the four possible stimulus-response events on the preceding trial; we denote these $\left(\mathrm{s}_{\mathrm{i}} \mathrm{r}_{\mathrm{j}}\right)_{\mathrm{n}}, \mathrm{i}, \mathrm{j}=1,2$. Norman (1972) has shown that, independent of any substantive assumptions about the $f_{i}(x)$, simple restrictions on the criterion shifts suffice to determine the asymptotic behavior of $\hat{p}_{\mathrm{N}}\left(\mathrm{r}_{2}\right)$ as $\mathrm{N} \rightarrow \infty$. Table 1 shows the cases of interest: the 2 by 2 tables give the criterion shift given particular $s_{i}$ (rows) and particular $r_{j}$ (columns) on the preceding trial. Note that $\delta, d_{i}>0$ throughout Table 1. All the models are, of course, specializations of a general deterministic model (GDM) with four distinct $\delta_{\mathrm{e}}$ parameters; at the other extreme lies the static criterion model (SCM), with all the $\delta_{\mathrm{e}}$ zero (viz, classical signal detection theory). Other special models are logically possible, but they are usually treated as either intuitively unacceptable (for example, after an error they make the criterion move so as to increase the probability of an error of that type on the next trial) or empirically unacceptable [because $\hat{\mathrm{p}}_{\mathrm{N}}\left(\mathrm{r}_{2}\right) \stackrel{\text { a.s. }}{\longrightarrow} 0$ or 1 ].

All of the viable special models, then, can be partially tested by observation of the $\hat{p}_{\mathrm{N}}\left(\mathrm{r}_{2}\right)$. In the case of DMM, the asymptotic variance is known; in the other cases, it can be estimated using the method described by Norman (1971), which uses the fact that all the models are second-order stationary. What gives the predictions about $\hat{p}_{N}\left(r_{2}\right)$ importance is, of course, the fact that they do not depend on assumptions about the $\mathrm{f}_{\mathrm{i}}(\mathrm{x})$.

An alternative, more assumption-bound approach is possible. Given $c_{0}$ (initial criterion position), the $\delta_{e}$, and a subject's stimulus-response protocol, the sequence $\left\{c_{0}, c_{1}, \ldots, c_{N}\right\}$ is recoverable. We can therefore calculate the likelihood of the data, conditional on particular $f_{j}(x), c_{0}, d_{e}$. If, on trial $n$, we get $\mathrm{s}_{\mathrm{i}} \mathrm{r}_{\mathrm{j}}$, then its contribution to the likelihood is of the form

$$
\gamma_{\mathrm{n}} \int_{\mathrm{c}}^{\lim _{\mathrm{j}}} \mathrm{f}_{\mathrm{i}}(\mathrm{x}) \mathrm{dx}
$$

in which $\gamma_{\mathrm{n}}$ is $\gamma,(1-\gamma)$ as $\mathbf{i}=1,2$, and $\lim _{\mathrm{j}}$ is $-\infty,+\infty$ as $\mathbf{j}=1,2$. The likelihood, then, is the
Table 1

Some Deterministic Additive Learning Models

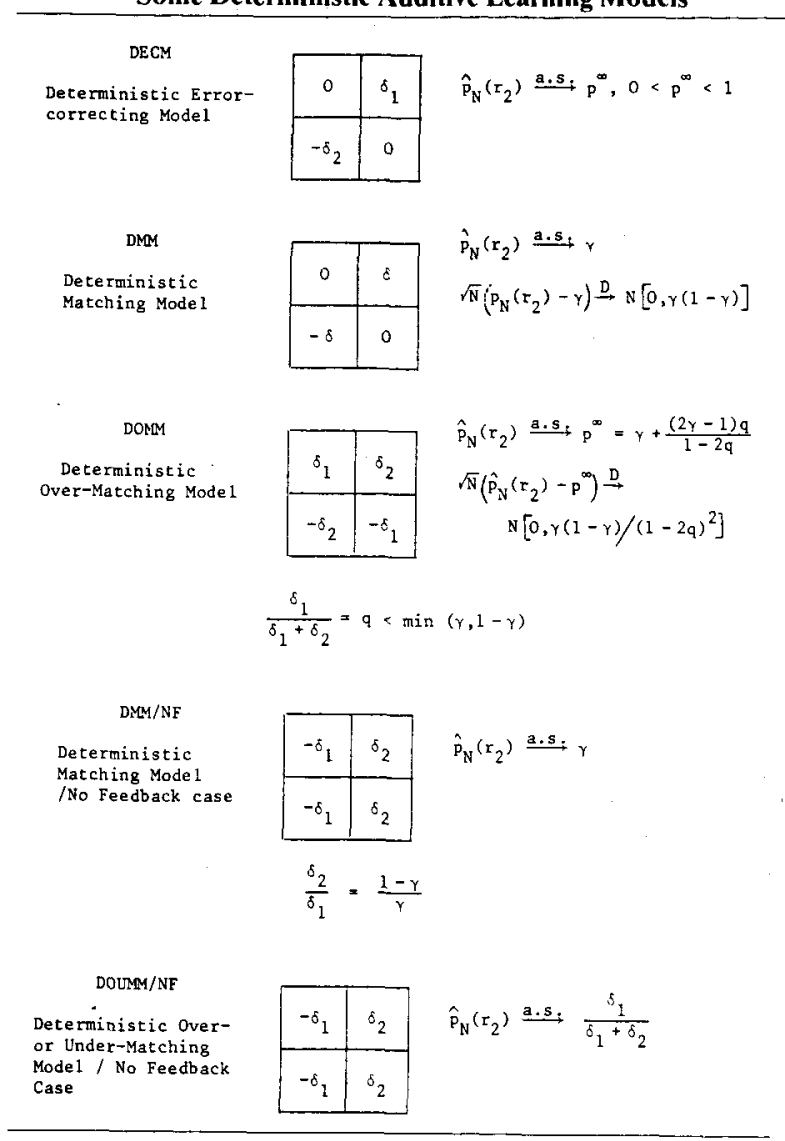

product of $\mathrm{N}$ such terms. By maximizing the likelihood (ignoring the constant term $\Pi \gamma_{n}$ ), we can estimate the discriminability and bias parameters conjointly, then compare a special to a more general model using likelihood-ratio tests (Kendall \& Stuart, 1973, section 24.7). Recall that, if $1_{s}, l_{g}$ are the (maximized) likelihoods for the special and general models, respectively, the special model has $r$ fewer parameters than the general model,

$$
-2 \log \left(l_{s} / 1_{g}\right)=-2 \log \lambda
$$

has an asymptotic chi-square distribution with $r$ degrees of freedom and a noncentrality parameter which reflects the "accuracy" of the model. In the case where the special model is correct, then the noncentrality parameter is zero and Equation 3 has the usual (central) chi-square distribution, $\mathrm{df}=\mathrm{r}$.

\section{Deterministic Models, $e=x_{n}-c_{n}$}

Only one model of this sort has been proposed (Thomas, 1975). In it, e represents the difference, $x_{n}-c_{n}$, observed on the preceding trial. It is assumed that the change in criterion, $\delta\left(x_{n}-c_{n}\right)$, is a bounded increasing function of $\left(x_{n}-c_{n}\right)$, and is symmetric in the sense $\delta(z)=-\delta(-z)$. The model predicts 
$\hat{\mathrm{p}}_{\mathrm{N}}\left(\mathrm{r}_{2}\right)<\gamma$ iff $\gamma>.5$, with $\gamma-\hat{\mathrm{p}}_{\mathrm{N}}\left(\mathrm{r}_{2}\right)$ decreasing with signal strength; it is called here the deterministic undermatching model, DUMM/NF. Apart from the undermatching prediction, the model appears untestable; since the event $e$ is unobservable, it is impossible to reconstruct the $\left\{c_{i}, i=1,2, \ldots, N\right\}$, given $c_{0}$, and so the likelihood approach cannot work.

\section{Probabilistic Models, $\mathbf{e}=\left(\mathbf{s}_{\mathbf{i}} \mathbf{r}_{\mathbf{j}}\right)_{\mathbf{n}}$}

Recall that, in general, probabilistic models assume

$$
c_{n+1}=c_{n}+\Delta_{e} . \quad \text { e } \varepsilon E
$$

In all but one of the cases investigated, it has been assumed that the distribution of the r.r.v. $\Delta_{\mathrm{e}}$ is of the form

$$
\Delta_{\mathrm{e}}=\left\{\begin{array}{l}
\delta_{\mathrm{e}} \\
0
\end{array}\right\} \text { with probability }\left\{\begin{array}{c}
\mathrm{p}_{\mathrm{e}} \\
1-\mathrm{p}_{\mathrm{e}}
\end{array}\right\},
$$

where $\delta_{\mathrm{e}}$ is either $+\delta$ or $-\delta$, depending on e. In the cases of this section, e just indexes the stimulusresponse pair on the preceding trial. Restrictions on the $p_{e}$ play the same role here as restrictions on the $\delta_{e}$ previously, and can be sufficient to guarantee probability matching or systematic departures from it, again without substantive assumptions about the $\mathrm{f}_{\mathrm{i}}(\mathrm{x})$. The cases of interest are given in Table 2: The 2 by 2 tables now give the shift probability

Table 2

Some Probabilistic Additive Learning Models

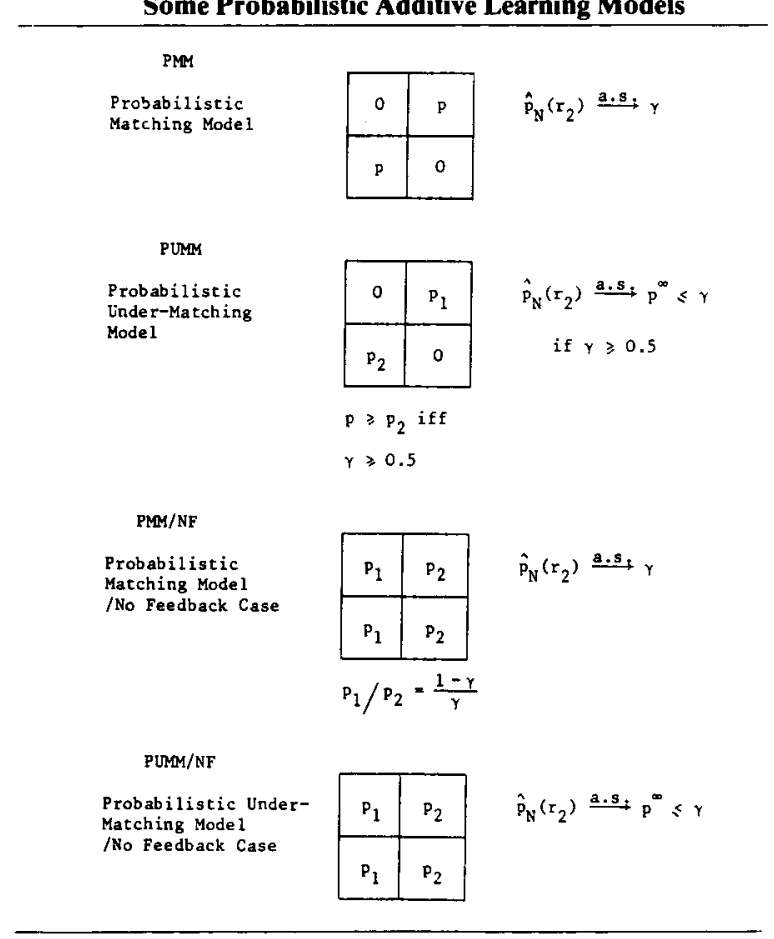

given the stimulus (rows) and the response (columns) on the preceding trial. As in the last section, the predictions about $\hat{\mathrm{p}}_{\mathrm{N}}\left(\mathrm{r}_{2}\right)$ provide the only means of testing the models: Here the e $\varepsilon \mathrm{E}$ are observable, but the $\left\{c_{i}, i=1,2, \ldots, N\right\}$ are not recoverable, so that, again, maximum likelihood estimation is not feasible. Thomas (1973) proposes a procedure for testing PMM against the corresponding general model (four distinct $\mathrm{p}_{\mathrm{e}}$ parameters); the procedure does not require parameter estimation and in that sense is nonparametric. Unfortunately, Thomas is able only to provide an order-of-magnitude type of result for the proposed statistic, the sampling distribution of which is unknown. This seems to make the procedure useless at present, as Dorfman et al. (1975) argue.

The one model in this section which does not conform to Equation 4 is due to Dorfman et al. (1975). They suppose that

$$
\Delta_{\mathrm{e}}=\delta_{\mathrm{e}}+\Delta
$$

$$
\delta_{\mathrm{e}}=\left\{\begin{array}{c}
0 \\
0 \\
-\delta \\
+\delta
\end{array}\right\} \operatorname{as~}\left(\mathrm{s}_{\mathrm{i}} \mathrm{r}_{\mathrm{j}}\right)_{\mathrm{n}}=\left\{\begin{array}{l}
\mathrm{s}_{1} \mathrm{r}_{1} \\
\mathrm{~s}_{2} \mathrm{r}_{2} \\
\mathrm{~s}_{2} \mathrm{r}_{1} \\
\mathrm{~s}_{1} \mathrm{r}_{2}
\end{array}\right\}
$$

where $\Delta$ is a r.r.v. representing "random drift"; $\Delta$ is assumed to have a discrete distribution with zero expectation and finite variance $\sigma_{\mathrm{c}}^{2}$ and to be independent of $c_{n-1}$. They show that

$$
\begin{aligned}
& \hat{\mathrm{p}}_{\mathrm{N}}\left(\mathrm{r}_{2}\right) \stackrel{\text { a.s. }}{\longrightarrow} \gamma \\
& \sqrt{\mathrm{N}}\left[\hat{\mathrm{p}}_{\mathrm{N}}\left(\mathrm{r}_{2}\right)-\gamma\right] \stackrel{\mathrm{D}}{\longrightarrow} \mathrm{N}\left[0, \gamma(1-\gamma)+\delta^{-2} \sigma_{\mathrm{c}}^{2}\right] .
\end{aligned}
$$

This model we refer to here as PMMRD, the probabilistic matching model with random drift.

\section{Probabilistic Models, $e=\left\langle\left(\mathbf{s}_{\mathbf{i}} \mathbf{r}_{\mathbf{j}}\right)_{\mathbf{n}}, \mathbf{x}_{\mathbf{n}}-\mathbf{c}_{\mathbf{n}}\right\rangle$}

Finally, we have Thomas' (1973, section 4) model in which the probability of criterion shift depends both on the preceding trial's stimulus-response pair and on $x_{n}-c_{n}$ :

$$
\begin{array}{ccc}
\mathrm{e} & \mathrm{p} & \delta_{\mathrm{e}} \\
\left\langle\left(\mathrm{s}_{1} \mathrm{r}_{1}\right)_{\mathrm{n}}, \mathrm{x}\right\rangle & 0 & - \\
\left\langle\left(\mathrm{s}_{2} \mathrm{r}_{2}\right)_{\mathrm{n}}, \mathrm{x}\right\rangle & 0 & - \\
\left\langle\left(\mathrm{s}_{1} \mathrm{r}_{2}\right)_{\mathrm{n}}, \mathrm{x}\right\rangle & \mathrm{f}(\mathrm{x}) & +\delta \\
\left\langle\left(\mathrm{s}_{2} \mathrm{r}_{1}\right)_{\mathrm{n}}, \mathrm{x}\right\rangle & \mathrm{f}(-\mathrm{x}) & -\delta
\end{array}
$$

where $f(0)=0$ and $f$ is increasing. Thomas shows that the model predicts undermatching, unless $f$ is a 
step function when matching results; hence, probabilistic undermatching Model 2 (PUMM2).

\section{Summary of Models}

A pictorial summary of the models appears as Table 3: $\mathrm{A} \Rightarrow \mathrm{B}$ denotes that result $\mathrm{A}$ is a special case of result $B ; \rightarrow$ is used to denote implication between a model and a result. $\left[p\left(r_{2}\right)\right]$ is the isobias curve family which keeps $p\left(r_{2}\right)$ constant over discriminability, as in Dusoir (1975). After each model, the integer in brackets gives the number of free bias parameters, including $\mathrm{c}_{0}$ (initial criterion position); for models which incorporate some function of $x_{n}-c_{n}$, we can only state the minimum number of bias parameters, allowing at least one for the function. To be quite explicit (pedantic), the predictions are those that follow if the parameters $\delta_{e}, p_{e}$ depend on payoff, instructions, possibly $\gamma$, but not discriminability. It is certainly logically possible to give up this latter assumption: Table 4 shows the result. Note that many of the models then give only the weakest of predictions about $\hat{\mathrm{p}}_{\mathrm{N}}\left(\mathrm{r}_{2}\right)$, so that it becomes unclear how to test them properly unless they permit the maximum likelihood approach. We refer later to "strong" and "weak" interpretations of ALMs, meaning Tables 3 and 4, respectively.

\section{EVIDENCE SO FAR: DORFMAN ET AL. (1975)}

Apart from the unsatisfactory evidence discussed in Dusoir (1975), Dorfman et al.'s (1975) reanalysis of the two-interval forced-choice sinusoid-in-noise detection data of Dorfman and Biderman (1971) provides the only direct evidence about ALMs; reanalysis was necessary because the earlier paper

Table 3

What ALMs Predict about $p\left(r_{2}\right)$ : Strong Interpretation

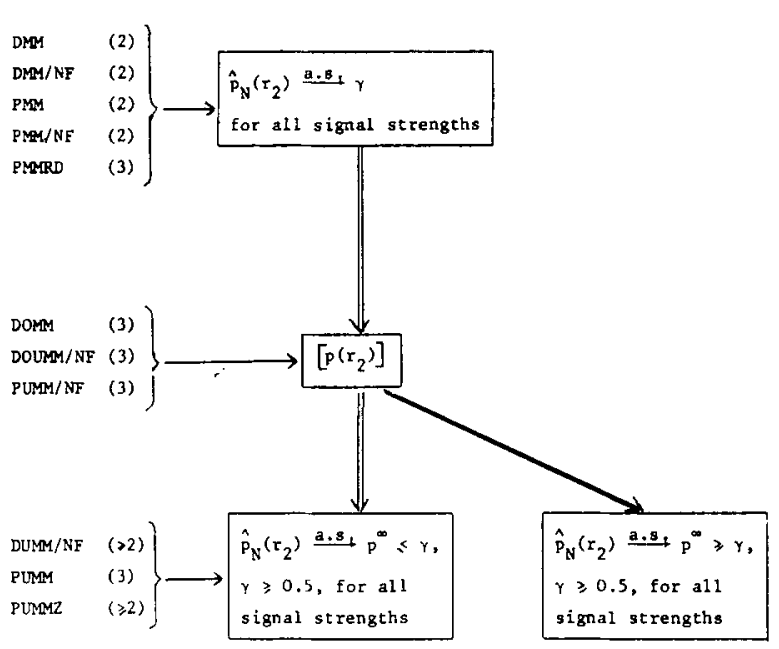

Table 4

What ALMs Predict about $p\left(r_{2}\right)$ : Weak Interpretation

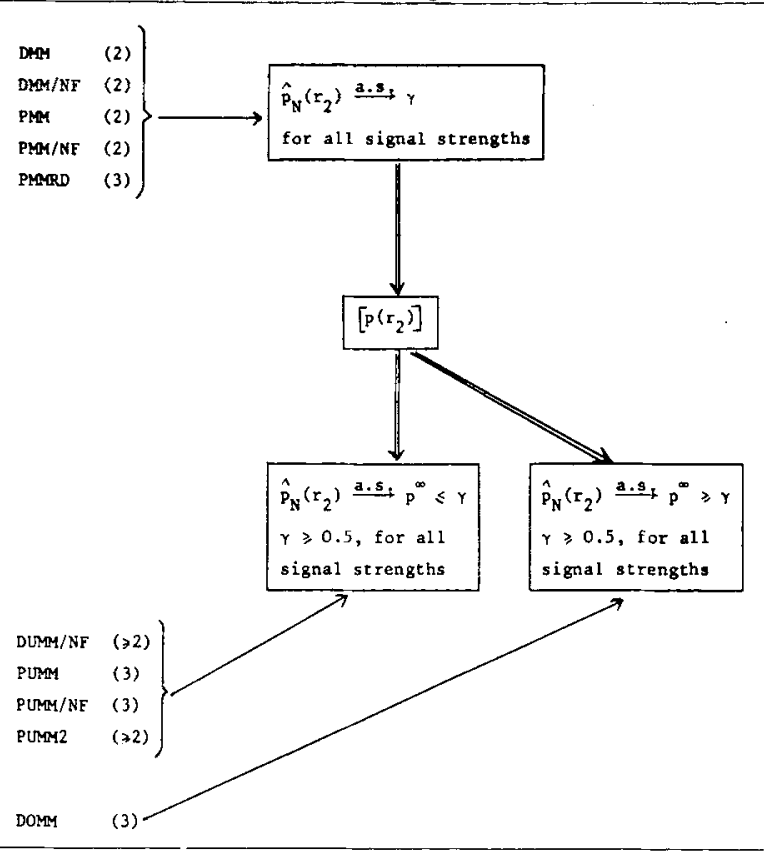

made a somewhat arbitrary assumption about $c_{0}$, rather than treating it as a free parameter.

\section{Argument from $\hat{\mathbf{p}}_{\mathrm{N}}\left(\mathbf{r}_{2}\right)$}

Dorfman et al. consider just DMM with its predictions (Norman's theorem):

$$
\begin{gathered}
\hat{\mathrm{p}}_{\mathrm{N}}\left(\mathrm{r}_{2}\right) \stackrel{\text { a.s. }}{\longrightarrow} \gamma \\
\sqrt{\mathrm{N}}\left[\hat{\mathrm{p}}_{\mathrm{N}}\left(\mathrm{r}_{2}\right)-\gamma\right] \stackrel{\mathrm{D}}{\longrightarrow} \mathrm{N}[0, \gamma(1-\gamma)]
\end{gathered}
$$

To evaluate Expression 9 independently of Expression 10, Dorfman et al. use the ordinary t statistic, with wholly nonsignificant results; this only shows matching in a group mean sense. Dorfman et al. sum up their tests of Expressions 9 and 10 conjointly as follows: "For trials 301-400 the support for Norman's theorem was extraordinarily good, with the variance of $\mathbf{P}_{\mathrm{mr}}^{\prime}$ only slightly larger than expectation." Note "variance," here, which is ambiguous between the sample $\left(\mathrm{s}^{2}\right)$ and population $\left(\sigma^{2}\right)$ variance. All we can say, applying Kendall and Stuart (1973, section 20.15) to Dorfman's data is

$$
\mathrm{p}\left(.65 \mathrm{~s}^{2}<\sigma^{2}<2.14 \mathrm{~s}^{2}\right)=.90,
$$

which is not too impressive: $\sigma^{2}$ could easily be more than twice the value of $\gamma(1-\gamma) \mathrm{N}^{-1}$ entailed by DMM.

\section{Likelihood Ratio Tests}

Dorfman et al. go on to carry out maximum likelihood estimation on the data of Trials 201-400, 
under the assumption that the $\mathrm{f}_{\mathrm{i}}(\mathrm{x})$ are equal variance normal. Their analysis makes the important assumption that the $\delta_{\mathrm{e}}$ parameters do not depend on $\gamma$. This does not seem especially plausible, even when, as here, subjects are not told $\gamma$; in a feedback task, differences in $\gamma$ become evident to the subject rather early, so that they could certainly alter $\delta_{e}$ accordingly after the first few trials.

The special models they consider against the general model with four $\delta_{e}$ parameters are DECM, DOMM, the static criterion model (all $\delta_{\mathrm{e}}=0$ ), and the pure change-when-correct model $\left(\delta_{\mathrm{e}}=0\right.$ for $e=s_{1} r_{2}$ or $s_{1} r_{2}, \delta_{e}=\delta$ for $e=s_{1} r_{1}, \delta_{e}=-\delta$ for $\left.e=s_{2} r_{2}\right)$. The last model was omitted from the earlier survey of ALMs because it predicts $\hat{p}_{\mathrm{N}}\left(\mathrm{r}_{2}\right)$ $\stackrel{\text { a.s. }}{\longrightarrow} 0$ or 1 ; it is included by Dorfman et al. as a check on the maximum likelihood procedure. Of these special models, DECM shows the lowest mean chi square, DOMM the next lowest. Note that DMM is a special case of both these models, and that the best fitting DECM gives $-\delta_{1}$ very close to $\delta_{2}$; this is some support for DMM. Nonetheless, all the special models do significantly worse than the general model.

One obvious feature of the maximum likelihood estimates is that the criterion shifts after correct responses are small and inconsistent in sign across subjects within the general model. Dorfman et al. confirm, by Monte Carlo methods, that small shifts after correct responses are sufficient to explain the poor fit of DECM. This leads them to introduce DMMRD, described earlier; recall that this model predicts matching, but makes $\hat{\mathrm{p}}_{\mathrm{N}}\left(\mathrm{r}_{2}\right)$ variance larger than Expression 10. It is important to note that the general model and DMMRD are quite distinguishable even at the level of the $\hat{p}_{N}\left(r_{2}\right)$ : the general model does not predict matching, though it may predict approximate group mean matching if the shifts after correct responses are small and inconsistent across subjects.

\section{Summary}

Dorfman et al.'s evidence on ALMs has some obvious limitations: (1) We certainly cannot generalize with confidence from a single (high) level of discriminability in a forced choice task with no explicit payoff to arbitrary discriminability and payoff in yes-no detection and recognition. (2) We cannot tell, from Dorfman's analysis, if individual subjects probability match, but with higher $\hat{p}_{N}\left(r_{2}\right)$ variance than follows from DMM, or, if matching occurs only at a group mean level. (3) Given that the general model does significantly better than all the special models, we cannot tell how well it does relative to other six-parameter models. (4) The assumption that the $\delta_{\mathrm{e}}$ are invariant under change in $y$ does not seem at all compelling.

\section{ON USING TIME SERIES ANALYSIS TO TEST THE MODELS}

The predictions about $\hat{\mathrm{p}}_{\mathrm{N}}\left(\mathrm{r}_{2}\right)$, though often qualitative, play an important part in testing ALMs: they do not depend on assumptions about the $f_{i}(x)$, and apart from them some of the special models are not testable at all. However, for only one case (DMM) does $\mathrm{p}_{\mathrm{N}}\left(\mathrm{r}_{2}\right)$ have a known distribution independent of the parameters; and for only one other case does $\mathrm{p}_{\mathrm{N}}\left(\mathrm{r}_{2}\right)$ have a known distribution at all (DOMM). Dorfman's solution, we have seen, was to retreat to the t statistic, except for DMM. This is weak, since, at best, it allows us to show something about group mean response rate; in order to draw conclusions about individual subjects, we need to be able to estimate $\hat{\mathrm{p}}_{\mathrm{N}}\left(\mathrm{r}_{2}\right)$ variance from the data. Here, in an exploratory spirit, Norman's (1971) method is used to do this; it should be pointed out that no general and rigorous account of the relation between additive models and the (weak) assumptions necessary for the method has yet been given. Only a bare statement of some useful results is given here; Anderson (1971) and Norman $(1971,1972)$ provide the background theory. Quite apart from ALMs, of course, the method bears on Thomas and Legge's (1970) proposal which is noncommittal about trial-by-trial events. The weak assumptions used here are almost certainly the minimum necessary to make their proposal formally testable at the level of individual subjects.

\section{The Method}

Suppose, for a single subject, that on the ith trial, $0 \leqslant \mathrm{i}<\mathrm{n}$, a random variable, $\mathrm{X}_{\mathrm{i}}$, takes the value 0 or 1 , where 0 corresponds to $r_{1}, 1$ to $r_{2}$. Disregarding the initial (probably transient) behavior, it is assumed that the shifted process $X_{m}, X_{m+1}, \ldots, X_{n}$ is secondorder stationary; that is, it is assumed that the expectation $\mathrm{E}\left(\mathrm{X}_{\mathrm{j}}\right)=\mu$ and the autocovariance of lag $\mathrm{k}$ $\operatorname{cov}\left(X_{j}, X_{j+k}\right)=c(k)$ both exist and do not depend on $\mathrm{j}$, also that $\Sigma|c(k)|$ is finite. Let

$$
\begin{aligned}
& N=n-m+1 \\
& X .=\sum_{j=m}^{n} X_{j} / N \\
& \hat{c}(k)=(1 / N) \sum_{j=m}^{n-k}\left(X_{j}-X .\right)\left(X_{j+k}-X .\right), \\
& \hat{\sigma}^{2}=\hat{c}(0)+2 \sum_{k=1}^{k} \hat{c}(k) .
\end{aligned}
$$


Thus, $\mathbf{N}$ gives the number of trials, $X$. the sample mean, and $\hat{c}(k)$ the sample autocovariance of lag $\mathbf{k}$. $\hat{\sigma}^{2}$ plays the same role as the sample variance in classical statistics. $K$ in Equation 14 is chosen so that $c(k)=0$ for $k>K$. Norman (1971) shows that the generalized $t$ statistic,

$$
\mathrm{t}=(\mathrm{X} .-\mu) \sqrt{\mathrm{N}} / \hat{\sigma},
$$

is asymptotically standard normal as $\mathbf{N} \rightarrow \infty$; sufficient conditions for this are given in Anderson (1971). If $t_{j}$ denotes the value of $t$ in Equation 15 for the jth of I subjects, then

$$
T=\sum_{j=1}^{1} t_{j} / \sqrt{ } I
$$

is also standard normal for sufficiently large $\mathbf{N}$ (Feller, 1971, p. 46) and

$$
\chi^{2}=\sum_{j=1}^{I} t_{j}^{2}
$$

is asymptotically chi square with I degrees of freedom (Mood \& Graybill, 1963, p. 227). The T statistic tests for the $(\mathrm{X} .-\mu)$ being large and systematic in sign across subjects, and the chi-square statistic tests for the $(X .-\mu)$ being too large regardless of sign.

Often there is no sound theoretical basis on which to choose $K$ in Equation 14, or any reason to assume identity of $\mathrm{K}$ across subjects; this is true here, as in Norman (1971). Fortunately, firm conclusions can often be reached, because the argument proves quite insensitive to choice of $\mathrm{K}$. A usefully modest statistic, from this point of view, is $\chi_{\min }^{2}(0 \leqslant K \leqslant M)$, defined analogously to Equation 17, except that $\mathrm{K}$ in Equation 14 is chosen for each subject separately, in the range $0 \leqslant K \leqslant M$, so as to maximize $\sigma^{2}$ and minimize | $\mathrm{t}$ | for that subject. $\mathrm{M}$, here, is chosen informally as a liberal upper bound to $\mathrm{K}$; $\mathbf{M}$ cannot simply be chosen as large as possible, since $K$ must be small relative to $\mathrm{N}$ for the estimator (14) to be consistent (Norman, 1971, p. 447). Thus, $\chi_{\min }^{2}(0 \leqslant K \leqslant M)$ provides a (very conservative) test for too large deviations $(X .-\mu)$ without committing the argument to any particular choice of $K$ in Equation 14 while allowing individual protocols to differ in their covariance structure and in $\sigma^{2}$.

Extension to the case where each subject generates two sequences, with no carry-over, is straightforward. The analogue of Equation 15 is

$$
t=\left[\left(X_{1}-X_{2}\right)-\left(\mu_{1}-\mu_{2}\right)\right] / \sqrt{\left(\hat{\sigma}_{1}^{2} / N_{1}+\hat{\sigma}_{2}^{2} / N_{2}\right)},
$$

where $N_{i}, X_{i}, \mu_{i}, \sigma_{\mathrm{i}}^{2}$ denote the number of trials, mean, expectation, and $\sigma^{2}$ estimate for the ith sequence. $t$ in Equation 18, like $t$ in Equation 15, is asymptotically standard normal as $\mathbf{N}_{1}$ and $\mathbf{N}_{\mathbf{2}} \rightarrow \infty$ (Norman, 1971); thus, the definition, asymptotic distribution, and use of $\mathrm{T}$ and chi square are exactly as above, except that one is now making inferences about $\left(\mu_{1}-\mu_{2}\right)$ rather than $\mu$. The $\chi_{\min }^{2}$ statistic, in this case, is defined so as to allow $K$ to be chosen separately for each sequence, not just for each subject.

\section{THE NO-FEEDBACK CASE}

Dusoir (1974) applied time series analysis to two auditory amplitude recognition tasks, and showed that at least some subjects do not conform either to $\left[\mathrm{p}\left(\mathrm{r}_{2}\right)\right]$ or to the matching hypothesis. This has serious implications for ALMs if we are expecting one special model to fit all subjects. Of the strong ALMs (Table 3), it argues against all but DUMM/NF, among the /NF models; but this model predicts undermatching, with $\gamma-p\left(r_{2}\right)$ decreasing with discriminability, and this is not compatible with Table 2 in Dusoir (1974): Subjects 5, 12, and 14 show grossly significant overmatching at one or the other of the two discriminability levels studied. Of the weak /NF ALMs (Table 4), the failure to match argues against $\mathrm{DMM} / \mathrm{NF}$ and $\mathrm{PMM} / \mathrm{NF}$, and the fact that some subjects overmatch against DUMM/NF, PUMM/NF. Of course, we can fit all the data with weak DOUMM/NF, or else fit different subjects with different special models; in neither case, then, are there simple $p\left(r_{2}\right)$ predictions of the kind considered here.

Before taking these negative results too seriously, it is worth examining whether they are peculiar to signal recognition tasks. Haller (1969), Tanner, Haller, and Atkinson (1967), and Tanner, Rauk, and Atkinson (1970) have argued that detection and recognition tasks show different sequential effects, different effects of feedback, and a different relation between $\gamma$ and $p\left(r_{2}\right)$ under /NF conditions. Perhaps the results above just confirm that, at least for the /NF case, ALMs and/or the general matching hypothesis should have been restricted to detection tasks. This possibility is examined next.

\section{EXPERIMENT 1: /NF DETECTION}

\section{Procedure}

Twelve subjects were run in an auditory detection task, $\gamma=.8$, with one of two symmetric payoffs, namely $o_{11}=o_{22}=+1$ point, $o_{12}=o_{21}=0$ point (six subjects, low payoff, Group L), or $o_{11}=o_{22}=+5$ points, $o_{12}=o_{21}=-5$ points (six subjects, high payoff, Group H), 25 points being worth $1 \mathrm{p}$. Group L, but not Group $\mathrm{H}$, had a basic payment of $60 \mathrm{p}$. Thus, the range of possible earnings was $60 p$ to $92 p(L)$ or $0 p$ to $160 p(H)$. The subjects were students at the City of London Polytechnic, with no recent exposure to other detection tasks.

The subjects heard continuous broadband noise through earphones. Every $4 \mathrm{sec}$, a warning light came on for $.5 \mathrm{sec}$ and was followed with probability .8 by the addition of a $1,000-\mathrm{Hz}$ sinusoid 
to the noise for $.5 \mathrm{sec}\left(\mathrm{s}_{2}\right)$. The subjects responded "no" or "yes" $\left(r_{1}, r_{2}\right)$ by means of two response keys. Assignment of keys to hands was balanced randomly within each group. Each subject took part in eight 100-trial blocks, with a 20 -min break between Blocks 4 and 5 , and a 2 -min break between the other blocks. Time series analysis is applied below to the last 85 trials of Block 8 .

The subjects were given a full account of the trial cycle and payoff matrix, and were told $\gamma$. They were invited to earn as much money as they could. At the end of the last block, the subjects were asked to estimate the proportion of trials in that block in which they had responded $r_{2}$. They were also asked what $y$ had been (all subjects replied correctly).

The equipment and the stimulus sequence generation were the same as in Dusoir (1974). The noise level was $78 \mathrm{~dB}$ SPL and $\mathrm{E} / \mathrm{N}_{0}$ was 14 .

\section{Results}

Table 5 gives $\hat{p}\left(r_{2}\right), \hat{p}\left(r_{2} \mid s_{1}\right)$, and $\hat{d}^{\prime}$ for each subject based on the last 85 trials of Block 8 . Group mean $r_{2}$ rates are slightly below the matching hypothesis prediction: .755 (L) and .771 (H). The subjects' retrospective estimates of $p\left(r_{2}\right)$ for the last block are also given.

To check the stationarity in a somewhat crude sense of these last 85 trials, number the last 85 trials from 1 to 85 , and define

$$
Y_{1}=\sum_{j=1}^{15} X_{j}, Y_{2}=\sum_{j=36}^{50} X_{j}, Y_{3}=\sum_{j=71}^{85} X_{j}
$$

Tests for upward trend in the $Y_{i}$ and for downward trend in $\left|\left(\mathrm{Y}_{\mathrm{i}} / 15-\gamma\right)\right|$ were carried out using Kendall's S statistic (Kendall, 1970, Sections 5.1-5.5). All results were nonsignificant $(p>.1)$.

The $\hat{c}(k)$ are comparable with those given in the earlier paper (Dusoir, 1974, Figure 1). Again, 20 is used as the upper bound $M$ for $K$ in Equation 14, but the $\hat{c}(k), k>0$, contribute rather little to $\hat{\sigma}^{2}$ :

Table 5

Results for Experiment 1

\begin{tabular}{ccccc}
\hline $\begin{array}{c}\text { Estimated } \\
\mathrm{p}\left(\mathrm{r}_{2}\right)\end{array}$ & $\hat{\mathrm{p}}\left(\mathrm{r}_{2}\right)$ & $\hat{\mathrm{p}}\left(\mathrm{r}_{2} \mid \mathrm{s}_{2}\right)$ & $\hat{\mathrm{d}}^{\prime}$ & $\mathrm{x}_{\min }^{2}$ \\
\hline \multicolumn{5}{c}{ Low Payoff } \\
.75 & .78 & .87 & 1.21 & .23 \\
.75 & .72 & .83 & 1.35 & 2.58 \\
.70 & .69 & .74 & .58 & $4.49^{*}$ \\
.70 & .71 & .78 & 1.10 & 3.63 \\
.85 & .72 & .72 & .09 & .71 \\
.75 & .92 & .97 & 1.62 & $13.06 \dagger$ \\
& & & & $24.69 \dagger$ \\
& & High Payoff & \\
.78 & .85 & .94 & 1.36 & 1.42 \\
.90 & .81 & .91 & 1.25 & .08 \\
.60 & .75 & .77 & .22 & .93 \\
.60 & .66 & .80 & 1.68 & $7.35^{* *}$ \\
.85 & .86 & .92 & 1.28 & 1.62 \\
.72 & .69 & .81 & 1.77 & 2.69 \\
& & & & $14.09^{*}$ \\
\hline
\end{tabular}

${ }^{*} p<.05 . \quad * * p<.01 . \quad+p<.001$. using $\bar{c}(k)$ for the group mean, $\hat{c}(k),|\vec{c}(k)|<.013$ for $\mathrm{k}=11$ to 20 , and average $\bar{c}(\mathrm{k})$ over the same range of $k$ is $.00165(\mathrm{~L})$ and $.00034(\mathrm{H})$.

In order to test for matching $(\mu=.8)$, Table 5 shows individual and group $\chi_{\min }^{2}(0 \leqslant K \leqslant 20)$ based on the last 85 trials of Block 8 . The matching hypothesis fails in both cases, though the evidence is stronger in the low-bias group. T does not reach significance in either group unless particular assumptions are made about $K$ in Equation 14: the deviations (X. $-\mu$ ) are too large, but probably not systematic in direction across subjects. Note that one subject shows gross overmatching $\left[\hat{p}\left(r_{2}\right)=.92, L\right.$ group], and one shows gross undermatching $\left[\hat{\mathrm{p}}\left(\mathrm{r}_{2}\right)=.66, \mathrm{H}\right.$ group $]$.

\section{CONCLUSION ABOUT THE /NF CASE}

The results are similar to those for recognition: both undermatching and overmatching sometimes occur, so that the only ALM, weak or strong, which can fit all subjects is the weak interpretation of DOUMM/NF.

To save the /NF ALMs, we have therefore to opt for weak DOUMM/NF or allow different models to fit different subjects. DOUMM/NF makes no predictions here, but yields constant $p\left(r_{2}\right)$ under change in $\gamma$ if the subject is unaware of the $\gamma$ changes, against the facts (Tanner et al., 1967, 1970). The second option is difficult to test, except weakly by checking that individual subjects continue to match/overmatch/undermatch as, say, $\gamma$ and discriminability are changed. We could also test the two deterministic models by inventing a plausible, more general model for the /NF case and using likelihood ratio tests; for example, the general model could make criterion shift depend on more than one preceding trial.

\section{EXPERIMENT 2: SIGNAL RECOGNITION WITH FEEDBACK}

This experiment differs from the preceding three in the presence of feedback, extensive pretraining, and the use of 200-trial blocks with a rather faster trial cycle so as to provide more uninterrupted trials for the maximum likelihood analysis.

\section{Method}

Procedure. Sixteen subjects took part in an auditory amplitude recognition task under two levels of discriminability, low (L) and high $(\mathrm{H})$, run in separate conditions. At each trial, a clearly audible $1,000-\mathrm{Hz}$ sinusoid was added to white pseudo-Gaussian noise. The noise stayed constant at $76 \mathrm{~dB}$ SPL throughout the experiment, and the $s_{2}$ (loud) signal level stayed at $161 \mathrm{mV} \mathrm{rms}$ at the earphones ( $72 \mathrm{~dB}$ SPL). The $s_{1}$ signal was either $149 \mathrm{mV}(\mathrm{L})$ or $140 \mathrm{mV}(\mathrm{H})(71.3$ or $70.8 \mathrm{~dB})$. $\gamma$ was .75 throughout, and the subjects were told this.

The trial cycle was as follows. A central red warning light came on for $.2 \mathrm{sec}$. At its offset, one of the two sinusoids was added for $.2 \mathrm{sec}$. There was then a 1.6-sec response interval, after which one of two white feedback lights came on for $1.5 \mathrm{sec}$ to indicate 
which signal had been present. At the offset of the feedback light, the warning light came on for the next trial.

The subject responded using two response keys, marked SOFT and LOUD. Assignment of responses to hands was balanced randomly across subjects. Payoff was symmetric: $\mathrm{O}_{11}=\mathrm{O}_{22}=$ $.5 \mathrm{p}, \mathrm{o}_{12}=\mathrm{o}_{21}=-.5 \mathrm{p}$. In addition, the subjects received $40 \mathrm{p}$ per session basic pay. They were told payoff at the end of each session.

Each subject ran for five sessions. A session included four 200-trial blocks, the first two at one discriminability level, the second two at the other. Order of $\mathrm{L}$ and $\mathrm{H}$ conditions was balanced randomly across subjects but fixed within subjects. Most of the analysis concerns just the final 200-trial block in each condition, obtained therefore after 1,800 practice trials at that discriminability level.

Sessions were irregularly spaced to fit in with subjects, but the experiment was always completed within 2 weeks.

Equipment. The experiment was controlled by a programming network built up from IC transistor logic elements. All the time intervals were derived from a $12-\mathrm{kHz}$ crystal-controlled squarewave oscillator, which, after frequency division and analogue filtering (distortion less than $.1 \%$ ), also provided the $1,000-\mathrm{Hz}$ sinusoid, gated at positive-going zero crossing. Up to 16 sinusoid voltages could be preset using Beckmann 10-turn helipots (linearity and resettable accuracy about $.05 \%$ ). A digital pseudorandom noise source was used with a maximal sequence length of $2^{31}-1$ and a clock frequency of $500 \mathrm{kHz}$, giving a cycle time of $72 \mathrm{~min}$; spacing between spectral lines was $.0002 \mathrm{~Hz}$; the $-.1-\mathrm{dB}$ point was at $40 \mathrm{kHz}$. The digital output was used to clock a ring counter, the 16 states of which could be patched many-one to the helipots to provide signal probabilities in multiples of $1 / 16$. The same noise, with frequencies above $15 \mathrm{kHz}$ filtered out, was mixed with the signal (when present) and passed through an audio amplifier (3-dB points at $10 \mathrm{~Hz}$ and $50 \mathrm{kHz}$ ) to Koss ESP9 electrostatic headphones.

Stimulus and response codes were marked by the experimenter onto optically read cards for later input to the DEC10, and in addition the various stimulus-response contingencies were recorded automatically on counters, making it possible to give end-of-block feedback and to cross-check the card records.

\section{Results and Discussion}

To check informally on approach to asymptote, $\hat{p}\left(r_{2}\right)$ was calculated over the last 152 trials of each block (48 trials was a convenient number to discard to allow for beginning-of-block warm-up because the optically read cards were decoded in 6-bit chunks). At a group mean level, the $\hat{p}\left(r_{2}\right)$ stabilize early and well. For the $L$ condition, group mean (SD) $\hat{p}\left(r_{2}\right)$ over the nine initial blocks were: $.78(.09), .77(.09)$, $.76(.09), .76(.06), .75(.08), .74(.06), .75(.06)$, $.76(.04), .76(.05)$. For $H$ they were: $.73(.05)$, $.73(.06), .73(.07), .73(.05), .74(.05), .74(.06)$, $.71(.05), .73(.04), .74(.05)$. The group standard deviations are quite large compared to the value $.035=\sqrt{[\gamma(1-\gamma) / \mathrm{N}]}$ expected from DMM, and rather larger than in Dorfman et al. (1975, Table 1), allowing for the difference in $\mathrm{N}$.

The results for the final 152 trials of the final block in each condition appear in Table 6 . The probabilities quoted are all one-tailed testwise probabilities. To test for crude nonstationarity, number the last 152 trials from 1 to 152 and define

$$
Y_{1}=\sum_{j=1}^{15} X_{j}, Y_{2}=\sum_{j=26}^{40} X_{j}, Y_{3}=\sum_{j=51}^{65} X_{j}, \ldots, Y_{6}=\sum_{j=126}^{140} X_{j}
$$

Note that here we are assuming $c(k)=0$ for $\mathrm{k}>10$. Tests for upward trend in the $Y_{i}$, and for downward trend in $\left|Y_{i} / 15-\gamma\right|$ were carried out, for both $L$ and $\mathrm{H}$ conditions; all four tests were nonsignificant, $\mathrm{p}>.1$.

Here 10 is used as the informally chosen upper bound $\mathrm{M}$ for $\mathrm{K}$ in Equation 14 as the $\hat{c}(\mathrm{k})$ seem to settle down to very small values rather more rapidly than in the earlier experiments (note that $\mathrm{N}$ is larger); using $\bar{c}(\mathbf{k})$ for the group mean $\hat{\mathrm{c}}(\mathrm{k}),|\overrightarrow{\mathrm{c}}(\mathrm{k})|<.008$ for $0<\mathrm{k} \leqslant 10$ and average $\bar{c}(k)$ over the same range of $k$ is $-.0017(\mathrm{~L})$ and $.00059(\mathrm{H})$.

The group mean $\hat{\mathrm{p}}\left(\mathrm{r}_{2}\right)$ are quite close to the matching prediction (Table 6 ). But the $\chi_{\min }^{2}$ to test for matching are grossly significant, and there are some individual cases of undermatching (S9, S10) and overmatching (S7, S11, S16).

The differences in $\hat{\mathrm{p}}\left(\mathrm{r}_{2}\right)$ between $\mathrm{L}$ and $\mathrm{H}$ conditions are mostly small and $\chi_{\min }^{2}$ to test $\mu_{1}=\mu_{2}$ is not significant. Nonetheless, the differences are very consistent in direction: only three subjects show $\hat{p}\left(r_{2}\right)$ smaller in the $\mathrm{L}$ condition. If we calculate $\mathrm{t}_{\min }$ for each subject (note that $t_{\min }^{2}=\chi_{\min }^{2}$ only if $t_{\min }>0$ ) and then use Equation 16, we find $T=2.793$, $p<.0025$, one-tailed. This calculation assumes that $\mathrm{K}$ is the same, within a given subject, for $\mathrm{L}$ and $\mathrm{H}$ conditions; if we drop this assumption, we still find $\mathrm{T}=2.584, \mathrm{p}<.006$. Thus, there is certainly a general tendency for $p\left(r_{2}\right)$ to decrease from $L$ to $H$ conditions.

Conclusions so far. Bearing in mind that we are going to be looking at these data using the maximum likelihood approach, here are the conclusions to be drawn provisionally from the $\hat{p}\left(r_{2}\right)$ data. We have at least five subjects who fail to match, two who undermatch, and three who overmatch; also, three subjects fail to conform to $\left[p\left(r_{2}\right)\right]$. As before, then, there is no question of a single special model fitting all subjects (see Tables 3 and 4). On the other hand, 13 of the $32 \hat{p}\left(r_{2}\right)$ are within \pm .02 of $\gamma, 22$ within \pm .04 , and half the subjects keep $\hat{\mathrm{p}}\left(\mathrm{r}_{2}\right)$ constant \pm .05 ; thus, matching and $\left[\mathrm{p}\left(\mathrm{r}_{2}\right)\right]$ describe some subjects rather well.

\section{LIKELIHOOD RATIO TESTS}

\section{Method}

Likelihood ratio tests are used here to compare DOMM, DECM, DMM, DOUMM/NF, DMM/NF, and SCM to the general deterministic model, GDM (the models are specified in Table 1). Two /NF models are included. Even if feedback is given, the subject may ignore it; and if this seems implausible, it is in any case quite useful to test some a priori implausible models as a rough check on the method of analysis. 
Table 6

Results of Experiment 2

\begin{tabular}{|c|c|c|c|c|c|c|c|c|}
\hline \multirow[b]{2}{*}{ Subject } & \multirow{2}{*}{$\begin{array}{l}\text { Discrim- } \\
\text { inability }\end{array}$} & \multirow[b]{2}{*}{$\hat{\mathrm{p}}\left(\mathrm{r}_{2} \mid \mathrm{s}_{2}\right)$} & \multirow[b]{2}{*}{$\hat{d}^{\prime}$} & \multirow[b]{2}{*}{$\hat{\mathbf{p}}\left(\mathrm{I}_{2}\right)$} & \multirow{2}{*}{$\begin{array}{c}\text { Matching } \\
x_{\min }^{2}\end{array}$} & \multirow{2}{*}{$\begin{array}{l}\mathrm{L}-\mathrm{H} \\
\mathrm{p}\left(\mathrm{r}_{2}\right)\end{array}$} & \multicolumn{2}{|c|}{$\left[\mathrm{p}\left(\mathrm{r}_{2}\right)\right]$} \\
\hline & & & & & & & $x_{\min }^{2}$ & $t_{\min }$ \\
\hline 1 & $\begin{array}{l}\text { Low } \\
\text { High }\end{array}$ & $\begin{array}{l}.9386 \\
.9615\end{array}$ & $\begin{array}{l}2.795 \\
3.152\end{array}$ & $\begin{array}{l}.7303 \\
.6842\end{array}$ & $\begin{array}{r}.193 \\
2.609\end{array}$ & .0460 & .580 & .762 \\
\hline 2 & $\begin{array}{l}\text { Low } \\
\text { High }\end{array}$ & $\begin{array}{l}.9316 \\
.9821\end{array}$ & $\begin{array}{l}2.330 \\
3.137\end{array}$ & $\begin{array}{l}.7632 \\
.7632\end{array}$ & $\begin{array}{l}.132 \\
.066\end{array}$ & .0000 & .000 & .000 \\
\hline 3 & $\begin{array}{l}\text { Low } \\
\text { High }\end{array}$ & $\begin{array}{l}.9182 \\
.9569\end{array}$ & $\begin{array}{l}2.030 \\
3.099\end{array}$ & $\begin{array}{l}.7368 \\
.7500\end{array}$ & $\begin{array}{l}.111 \\
.000\end{array}$ & -.0132 & .046 & -.265 \\
\hline 4 & $\begin{array}{l}\text { Low } \\
\text { High }\end{array}$ & $\begin{array}{l}.8454 \\
.8860\end{array}$ & $\begin{array}{l}1.137 \\
1.472\end{array}$ & $\begin{array}{l}.7368 \\
.7632\end{array}$ & $\begin{array}{l}.089 \\
.108\end{array}$ & -.0263 & .196 & -.628 \\
\hline 5 & $\begin{array}{l}\text { Low } \\
\text { High }\end{array}$ & $\begin{array}{l}.8640 \\
.9035\end{array}$ & $\begin{array}{l}1.634 \\
2.421\end{array}$ & $\begin{array}{l}.7632 \\
.7105\end{array}$ & $\begin{array}{r}.121 \\
1.131\end{array}$ & .0526 & 1.090 & 1.044 \\
\hline 6 & $\begin{array}{l}\text { Low } \\
\text { High }\end{array}$ & $\begin{array}{l}.8559 \\
.8482\end{array}$ & $\begin{array}{r}.914 \\
1.029\end{array}$ & $\begin{array}{l}.7895 \\
.7566\end{array}$ & $\begin{array}{r}1.425 \\
.036\end{array}$ & .0329 & .469 & .685 \\
\hline 7 & $\begin{array}{l}\text { Low } \\
\text { High }\end{array}$ & $\begin{array}{l}.8898 \\
.9237\end{array}$ & $\begin{array}{r}.504 \\
2.060\end{array}$ & $\begin{array}{l}.8618 \\
.7763\end{array}$ & $\begin{array}{c}12.841 \dagger \\
.455\end{array}$ & .0855 & 3.504 & $1.872^{*}$ \\
\hline 8 & $\begin{array}{l}\text { Low } \\
\text { High }\end{array}$ & $\begin{array}{l}.9550 \\
.9460\end{array}$ & $\begin{array}{l}2.171 \\
2.659\end{array}$ & $\begin{array}{l}.7829 \\
.7303\end{array}$ & $\begin{array}{l}.968 \\
.283\end{array}$ & .0526 & 1.147 & 1.071 \\
\hline 9 & $\begin{array}{l}\text { Low } \\
\text { High }\end{array}$ & $\begin{array}{l}.7875 \\
.8427\end{array}$ & $\begin{array}{l}.867 \\
.986\end{array}$ & $\begin{array}{l}.6382 \\
.7039\end{array}$ & $\begin{array}{l}6.597^{*} \\
.986\end{array}$ & -.0658 & 1.147 & -1.281 \\
\hline 10 & $\begin{array}{l}\text { Low } \\
\text { High }\end{array}$ & $\begin{array}{l}.7693 \\
.7826\end{array}$ & $\begin{array}{r}.828 \\
1.166\end{array}$ & $\begin{array}{l}.7105 \\
.6118\end{array}$ & $\begin{array}{c}.920 \\
9.780^{* *}\end{array}$ & .0987 & 3.038 & $1.743^{*}$ \\
\hline 11 & $\begin{array}{l}\text { Low } \\
\text { High }\end{array}$ & $\begin{array}{l}.9333 \\
.9907\end{array}$ & $\begin{array}{r}.491 \\
2.006\end{array}$ & $\begin{array}{l}.9145 \\
.8882\end{array}$ & $\begin{array}{l}45.931 \dagger \\
25.534 \dagger\end{array}$ & .0263 & .585 & .765 \\
\hline 12 & $\begin{array}{l}\text { Low } \\
\text { High }\end{array}$ & $\begin{array}{l}.9364 \\
.8942\end{array}$ & $\begin{array}{l}1.891 \\
2.062\end{array}$ & $\begin{array}{l}.7763 \\
.6776\end{array}$ & $\begin{array}{r}.591 \\
1.538\end{array}$ & .0987 & 2.267 & 1.506 \\
\hline 13 & $\begin{array}{l}\text { Low } \\
\text { High }\end{array}$ & $\begin{array}{l}.9487 \\
.9820\end{array}$ & $\begin{array}{l}2.700 \\
3.262\end{array}$ & $\begin{array}{l}.7632 \\
.7500\end{array}$ & $\begin{array}{l}.146 \\
.000\end{array}$ & .0132 & .072 & .267 \\
\hline 14 & $\begin{array}{l}\text { Low } \\
\text { High }\end{array}$ & $\begin{array}{l}.9016 \\
.9561\end{array}$ & $\begin{array}{l}1.914 \\
3.646\end{array}$ & $\begin{array}{l}.7763 \\
.7237\end{array}$ & $\begin{array}{l}.442 \\
.427\end{array}$ & .0526 & .869 & .932 \\
\hline 15 & $\begin{array}{l}\text { Low } \\
\text { High }\end{array}$ & $\begin{array}{l}.9636 \\
.9546\end{array}$ & $\begin{array}{l}2.036 \\
3.000\end{array}$ & $\begin{array}{l}.8092 \\
.7171\end{array}$ & $\begin{array}{r}3.329 \\
.509\end{array}$ & .0921 & 3.229 & $1.797^{*}$ \\
\hline \multirow[t]{2}{*}{16} & $\begin{array}{l}\text { Low } \\
\text { High }\end{array}$ & $\begin{array}{l}.9141 \\
.9746\end{array}$ & $\begin{array}{l}1.577 \\
3.002\end{array}$ & $\begin{array}{l}.8355 \\
.7895\end{array}$ & $\begin{array}{l}3.964^{*} \\
1.401\end{array}$ & .0460 & .812 & .901 \\
\hline & & & \multicolumn{2}{|c|}{ Low Discriminability } & & & & \\
\hline \multirow{2}{*}{\multicolumn{2}{|c|}{$\begin{array}{l}\text { Mean } \\
\text { SD } \\
\Sigma(\mathrm{df}=16) \\
\Sigma / \sqrt{16}\end{array}$}} & $\begin{array}{l}.897 \\
.058\end{array}$ & $\begin{array}{r}1.614 \\
.744\end{array}$ & $\begin{array}{l}.7743 \\
.0634\end{array}$ & $77.8 \dagger$ & $\begin{array}{l}.0371 \\
.0469\end{array}$ & 19.05 & $2.79 * *$ \\
\hline & & & \multicolumn{2}{|c|}{ High Discriminability } & & & & \\
\hline $\begin{array}{l}\text { Mean } \\
\text { SD } \\
\Sigma(\mathrm{df}=\end{array}$ & & $\begin{array}{l}.924 \\
.060\end{array}$ & $\begin{array}{r}2.385 \\
.869\end{array}$ & $\begin{array}{l}.7372 \\
.0598\end{array}$ & $44.9 \dagger$ & & & \\
\hline
\end{tabular}

$* p<.05 . \quad * * p<.0025 . \quad t p<.001$.

Recall that for the maximum likelihood analysis we need to specify the distributions $f_{i}(x)$. It is assumed here that $f_{1}(x) \sim N[0,1]$, $f_{2}(x) \sim N[d, 1]$, as in Dorfman et al. The model parameters therefore are $\mathrm{d}$ (separation between the distributions), $\mathrm{c}_{0}$ (initial criterion position), and the $\delta_{\mathrm{ij}}$ (criterion shifts); $\delta_{\mathrm{ij}}$ just denotes the criterion shift after $s_{i} r_{j}$. The models differ just in what restrictions, if any, they impose on the $\delta_{i j}$.

The log likelihood, then, has the form

$\log 1=m_{1} \log (1-\gamma)+m_{2} \log (\gamma)+\sum_{n} \log \left[\int_{c_{n}}^{\lim _{n_{n}}} f_{(n)}(x) d x\right], \quad$ (19) where $n$ indexes trials; $m_{i}$ is the number of $s_{i}$ trials; $\lim _{n}$ is $-\infty,+\infty$ as the response on trial $n$ is $r_{1} r_{2} ; f_{(n)}(x)$ is $f_{1}(x), f_{2}(x)$ as the stimulus on trial $n$ is $s_{1}, s_{2}$, and only the last term has to be maximized.

The analysis was carried out by a Fortran program written by the author; Shenton's (1954) continued fraction was used to approximate the integrals in Equation 19, and the Nottingham algorithms group routine E04CAF was used to perform the maximization; this routine uses the search method of Fletcher and Powell (1963) (on the convergence issue, see Polak, 1971, and Dorfman, 1973). Note that the $\delta, d_{1}>0$ assumption of Table 1 was not imposed on the maximization, and that all parameters were free to vary between $\mathrm{L}$ and $\mathrm{H}$ conditions, as in weak ALMs. 


\section{Results}

The analysis was applied to the final 200-trial block in each condition. Table 7 gives the mean parameter estimates and their standard deviations, and for each special model an overall chi square, obtained by summing individual chi-square values (see Equation 3).

General features of the results. To get some preliminary orientation, note the general features of Table 7. d estimates are systematically lower under $\mathrm{SCM}$, as this model confounds any criterion variance present with discriminability; but the differences in $d$ across models are really quite small, which illustrates why $\hat{\mathrm{d}}^{\prime}$ can remain a useful measure when SCM is doubtful. $c_{0}$ for all models is displaced downwards from the central $c=d / 2$ position (appropriately given $\gamma$ ). The standard deviations of the $\hat{c}_{0}$ are large, as might be expected given the large $d$ variability; in fact, however, within individual subjects there is, in any case, large variation in $\hat{c}_{0}$ across models, despite roughly constant $d$. The feedback models GDM and DMM make $\delta$ much greater, on average, after errors than after correct responses. The model DOUMM/NF makes $\delta$ greater after the infrequent response $r_{1}$ than after $r_{2}$.

Evaluation of the special models. The earlier $p\left(r_{2}\right)$ results showed that none of the special models could fit all the subjects. This is confirmed here by the high overall chi-square values for all models.
In view of Dorfman et al.'s (1975) reasonable objection to summing the (possibly biased) chi square, Table 7 also gives the number of individual values which are significant at $\alpha=.05$ and at $\alpha=.005$ [the latter yields a groupwise error rate of $\alpha^{\prime}=.04$ using $\left.\alpha^{\prime}=1-(1-\alpha)^{\mathrm{n}}\right]$. Whichever of these indices one looks at, the special models fail: SCM, as might be expected, is especially poor, as is DMM/NF; but DOUMM/NF appears to do not much worse than any of the feedback models. Table 7 also gives the number of "small" chi-square values $(p>.25)$ : DOMM, DECM, DMM each fit about a third of the cases quite well.

Evaluation of GDM. As in Dorfman's data, the mean criterion shift after errors is larger than after correct responses, within the GDM model, but there is strong asymmetry, $-\delta_{11} \neq \delta_{22}, \delta_{12} \neq-\delta_{21}$. One obvious ad hoc explanation is that the $\delta_{\mathrm{ij}}$ reflect the unequal signal probabilities, as against Dorman's a priori assumption. Note also that the mean $d_{11}$ results from a combination of some really large positive and negative values; we are far from Dorfman's suggestion of "small $\delta_{i i}$ inconsistent in direction across subjects." A common pattern, in fact, is $\delta_{11}, \delta_{21}<0, \delta_{12}, \delta_{22}>0$, with $-\delta_{11}$ substantial; that is, the response event determines the sign of $\delta_{\mathrm{ij}}$ and the stimulus event modifies its magnitude.

Evidence against the strong interpretation of GDM is provided by the often enormous differences in the

Table 7

Mean Estimates and $x^{2}=-2 \log \lambda$ for Experiment 2

\begin{tabular}{|c|c|c|c|c|c|c|c|c|c|c|c|c|c|c|c|c|c|}
\hline \multirow{2}{*}{$\begin{array}{l}\text { Discrim- } \\
\text { inability }\end{array}$} & \multicolumn{2}{|c|}{$\mathrm{d}$} & \multicolumn{2}{|c|}{$\mathrm{c}_{0}$} & \multicolumn{2}{|c|}{$\delta_{11}$} & \multicolumn{2}{|c|}{$\delta_{12}$} & \multicolumn{2}{|c|}{$\delta_{21}$} & \multicolumn{2}{|c|}{$\delta_{22}$} & \multirow{2}{*}{\multicolumn{2}{|c|}{$x^{2 *} x^{2 * *}$}} & \multirow[b]{2}{*}{$\Sigma \chi^{2}$} & \multirow{2}{*}{\multicolumn{2}{|c|}{ df $x^{2}+\dagger$}} \\
\hline & Mean & SD & Mean & SD & Mean & SD & Mean & SD & Mean & SD & Mean & SD & & & & & \\
\hline \multicolumn{18}{|c|}{ GDM } \\
\hline $\begin{array}{l}\text { Low } \\
\text { High }\end{array}$ & $\begin{array}{l}1.712 \\
2.631\end{array}$ & $\begin{array}{l}.868 \\
.890\end{array}$ & $\begin{array}{r}.456 \\
1.154\end{array}$ & $\begin{array}{l}1.063 \\
1.081\end{array}$ & $\begin{array}{l}-.1480 \\
-.0310\end{array}$ & $\begin{array}{l}.323 \\
.162\end{array}$ & $\begin{array}{l}.2450 \\
.3920\end{array}$ & $\begin{array}{l}.191 \\
.409\end{array}$ & $\begin{array}{l}-.4400 \\
-.4560\end{array}$ & $\begin{array}{l}.241 \\
.388\end{array}$ & $\begin{array}{l}.0510 \\
.0100\end{array}$ & $\begin{array}{l}.064 \\
.051\end{array}$ & & & & & \\
\hline \multicolumn{18}{|c|}{ DOMM } \\
\hline $\begin{array}{l}\text { Low } \\
\text { High }\end{array}$ & $\begin{array}{l}1.614 \\
2.558\end{array}$ & $\begin{array}{l}.763 \\
.818\end{array}$ & $\begin{array}{r}.321 \\
1.138\end{array}$ & $\begin{array}{l}.725 \\
.995\end{array}$ & $\begin{array}{r}.0070 \\
-.0003\end{array}$ & $\begin{array}{l}.017 \\
.025\end{array}$ & $\begin{array}{l}.1640 \\
.2960\end{array}$ & $\begin{array}{l}.108 \\
.274\end{array}$ & $\begin{array}{l}-.1640 \\
-.2960\end{array}$ & & $\begin{array}{l}-.0010 \\
+.0003\end{array}$ & & $\begin{array}{l}7 \\
4\end{array}$ & $\begin{array}{l}4 \\
0\end{array}$ & $\begin{array}{r}141.96 \dagger \\
49.46^{*}\end{array}$ & $\begin{array}{l}32 \\
32\end{array}$ & $\begin{array}{r}3 \\
10\end{array}$ \\
\hline \multicolumn{18}{|c|}{ DECM } \\
\hline $\begin{array}{l}\text { Low } \\
\text { High }\end{array}$ & $\begin{array}{l}1.627 \\
2.534\end{array}$ & $\begin{array}{l}775 \\
.802\end{array}$ & $\begin{array}{r}.453 \\
1.115\end{array}$ & $\begin{array}{l}.658 \\
.987\end{array}$ & & & $\begin{array}{l}.1740 \\
.2960\end{array}$ & $\begin{array}{l}.103 \\
.315\end{array}$ & $\begin{array}{l}-.2430 \\
-.2860\end{array}$ & $\begin{array}{l}.152 \\
.182\end{array}$ & & & $\begin{array}{l}5 \\
4\end{array}$ & $\begin{array}{l}3 \\
0\end{array}$ & $\begin{array}{c}117.84 \dagger \\
58.90^{* *}\end{array}$ & $\begin{array}{l}32 \\
32\end{array}$ & $\begin{array}{l}6 \\
6\end{array}$ \\
\hline \multicolumn{18}{|c|}{ DMM } \\
\hline $\begin{array}{l}\text { Low } \\
\text { High }\end{array}$ & $\begin{array}{l}1.559 \\
2.482\end{array}$ & $\begin{array}{l}.760 \\
.770\end{array}$ & $\begin{array}{l}.291 \\
.999\end{array}$ & $\begin{array}{l}.645 \\
.878\end{array}$ & & & $\begin{array}{l}.0770 \\
.1700\end{array}$ & $\begin{array}{l}.096 \\
.121\end{array}$ & $\begin{array}{l}-.0770 \\
-.1700\end{array}$ & & & & $\begin{array}{r}10 \\
3\end{array}$ & $\begin{array}{l}3 \\
0\end{array}$ & $\begin{array}{r}177.65 \dagger \\
84.19 \dagger\end{array}$ & $\begin{array}{l}48 \\
48\end{array}$ & $\begin{array}{l}3 \\
7\end{array}$ \\
\hline \multicolumn{18}{|c|}{ DOUMM/NF } \\
\hline $\begin{array}{l}\text { Low } \\
\text { High }\end{array}$ & $\begin{array}{l}1.643 \\
2.442\end{array}$ & $\begin{array}{l}.877 \\
.769\end{array}$ & $\begin{array}{l}.354 \\
.924\end{array}$ & $\begin{array}{l}.703 \\
.732\end{array}$ & $\begin{array}{l}-.1620 \\
-.0840\end{array}$ & $\begin{array}{l}.143 \\
.104\end{array}$ & $\begin{array}{l}.0460 \\
.0270\end{array}$ & $\begin{array}{l}.040 \\
.036\end{array}$ & $\begin{array}{l}-.1620 \\
-.0840\end{array}$ & & $\begin{array}{l}.0460 \\
.0270\end{array}$ & & $\begin{array}{r}10 \\
5\end{array}$ & $\begin{array}{l}2 \\
1\end{array}$ & $\begin{array}{r}109.24 \dagger \\
75.96 \dagger\end{array}$ & $\begin{array}{l}32 \\
32\end{array}$ & $\begin{array}{l}3 \\
5\end{array}$ \\
\hline \multicolumn{18}{|c|}{$\mathrm{DMM} / \mathrm{NF}$} \\
\hline $\begin{array}{l}\text { Low } \\
\text { High }\end{array}$ & $\begin{array}{l}1.542 \\
2.414\end{array}$ & $\begin{array}{l}.748 \\
.752\end{array}$ & $\begin{array}{l}.225 \\
.855\end{array}$ & $\begin{array}{l}.528 \\
.619\end{array}$ & $\begin{array}{l}-.0430 \\
-.0380\end{array}$ & $\begin{array}{l}.069 \\
.083\end{array}$ & $\begin{array}{l}.0140 \\
.0130\end{array}$ & & $\begin{array}{l}-.0430 \\
-.0380\end{array}$ & & $\begin{array}{l}.0140 \\
.0130\end{array}$ & & $\begin{array}{r}11 \\
8\end{array}$ & $\begin{array}{l}5 \\
0\end{array}$ & $\begin{array}{l}178.40^{\dagger} \\
114.20^{\dagger}\end{array}$ & $\begin{array}{l}48 \\
48\end{array}$ & $\begin{array}{l}2 \\
3\end{array}$ \\
\hline \multicolumn{18}{|c|}{$\mathrm{SCM}$} \\
\hline $\begin{array}{l}\text { Low } \\
\text { High }\end{array}$ & $\begin{array}{l}1.530 \\
2.396\end{array}$ & $\begin{array}{l}.740 \\
.745\end{array}$ & $\begin{array}{l}.252 \\
.858\end{array}$ & $\begin{array}{l}.542 \\
.576\end{array}$ & & & & & & & & & $\begin{array}{r}11 \\
7\end{array}$ & $\begin{array}{l}5 \\
1\end{array}$ & $\begin{array}{l}212.54 \dagger \\
141.89 \dagger\end{array}$ & $\begin{array}{l}64 \\
64\end{array}$ & $\begin{array}{l}0 \\
2\end{array}$ \\
\hline
\end{tabular}

Note-SDs are not given in instances in which parameters were not free. $\quad{ }^{*} p<.05 . \quad *_{*}^{*} p<.005 . \quad+p<.001 . \quad+t_{p}>.25$. 
Table 8

Mean Parameter Estimates for Experiment 2 Assuming RRM

\begin{tabular}{|c|c|c|c|c|c|c|c|c|c|c|c|c|}
\hline \multirow[b]{2}{*}{ Payoff } & \multicolumn{2}{|c|}{$\mathrm{d}$} & \multicolumn{2}{|c|}{$c_{0}$} & \multicolumn{2}{|c|}{$\mathrm{k}_{1}$} & \multicolumn{2}{|c|}{$k_{2}$} & \multicolumn{2}{|c|}{$\delta_{1}$} & \multicolumn{2}{|c|}{$\delta_{2}$} \\
\hline & Mean & $\mathrm{SD}$ & Mean & SD & Mean & SD & Mean & $\mathrm{SD}$ & Mean & SD & Mean & SD \\
\hline Low & 1.578 & .844 & .493 & .794 & 1.75 & .93 & 8.81 & 5.67 & -.361 & .383 & .423 & .441 \\
\hline High & 2.534 & .814 & .864 & .809 & 2.68 & 1.35 & 7.88 & 4.01 & -.574 & .672 & .382 & .511 \\
\hline
\end{tabular}

best fitting $\delta_{\mathrm{ij}}$ across $\mathrm{L}$ and $\mathrm{H}$ conditions. The mean absolute differences over the 16 subjects are .284 $\left(\delta_{11}\right), .283\left(\delta_{12}\right), .382\left(\delta_{21}\right), .064\left(\delta_{22}\right)$.

Since weak GDM is not itself tested in the foregoing analysis, it is next compared with two other models with respect to maximized $\log 1$. The first rival model considered is an entirely ad hoc response runs model (RRM); this is identical to GDM except in the rule governing criterion shift. The rule in RRM is that, given response $r_{j}$, the criterion shifts by $\delta_{j}$ if the $r_{j}$ completes a response run of length $k_{j}$, and otherwise stays where it is, so that there are six parameters, $\mathrm{d}, \mathrm{c}_{0}, \mathrm{k}_{1}, \mathrm{k}_{2}, \delta_{1}$, and $\delta_{2}$. To fit this model to the last block data of Experiment 2, $\log 1$ was maximized over $\mathrm{d}, \mathrm{c}_{0}, \delta_{1}$, and $\delta_{2}$, using E04CAF for each $k_{1}, k_{2}$ combination separately $\left(k_{1}, k_{2}\right.$ must be no greater than the largest response run in the data), and then these maxima were maximized over $k_{1}, k_{2}$. Table 8 gives the mean estimates obtained. To check convergence, a quarter of the analyses were rerun using different starting points, with identical results.

The second rival model considered is the fiveparameter memory recognition model (MRM) of Tanner et al. (1970). According to this model

$$
\begin{aligned}
& \mathrm{p}\left(\mathrm{r}_{2} \mid \mathrm{s}_{\mathrm{i}} \mathrm{s}_{\mathrm{j}} \mathrm{r}_{\mathrm{k}}\right) \\
& \left.\quad=\omega \Phi\left[\mathrm{s}_{\mathrm{i}}-\mathrm{t}_{\mathrm{j}}-\delta_{\mathrm{j}}\right) / \sigma_{\mathrm{D}}\right]+(1-\omega) \Phi\left[\left(\mathrm{s}_{\mathrm{i}}-\mathrm{t}_{\mathrm{j}}-\delta_{\mathrm{k}}\right) / \sigma_{\mathrm{D}}\right],
\end{aligned}
$$

where $p\left(r_{2} \mid s_{i} s_{j} r_{k}\right)$ is the probability of $r_{2}$, given $s_{i}$ on the current trial and $s_{j} r_{k}$ on the preceding trial. Equation 20 arises from the assumption that at each trial the current input is compared with a memory trace of the preceding input, resulting in normal difference distributions with means $s_{i}-t_{j}$ (i indexes the current and $j$ the preceding signal) and constant variance $\sigma_{\mathrm{D}}^{2}$. The $s_{\mathrm{i}}$ are treated as scaling parameters and set to $s_{1}=0, s_{2}=1$. The $t_{j}$ are assumed to depend linearly on $\gamma: \mathrm{t}_{1}=(1-\alpha) \gamma, \mathrm{t}_{2}=\alpha+(1-\alpha) \gamma$, where $0 \leqslant \alpha \leqslant 1$. The subject is assumed to have two criteria: $\delta_{1}, \delta_{2} \geqslant \delta_{1}$. If the current difference is small $\left(<\delta_{1}\right)$, the subject responds $r_{1}$; if it is large $\left(>\delta_{2}\right)$, he responds $r_{2}$; if neither, he chooses probabilistically whether to repeat the response he made on the previous trial or to give the response that was correct on the previous trial: $\omega$ in Equation 20 weights these two alternatives $(0 \leqslant \omega \leqslant 1)$. Thus the parameters are $\alpha, o_{\mathrm{D}}, \delta_{1}, \delta_{2}, \omega$. The model seems to have identifiability problems, which Tanner et al. do not mention. It can easily be checked, for example, that the parameter vectors $(.122, .384,-.22$, $-.39,1.0),(.811, .384, .3,-.56,1.0)$ produce identical (up to rounding error) sequential probabilities. The problem here is just to be sure that any local maximum found is also the possibly nonunique global maximum. First, $\log 1$ was maximized using E04CAF from four different starting points. Second, $\log 1$ was maximized using direct grid search, with a rather coarse grid because of time limitations: .01 for $\sigma_{\mathrm{D}}, .1$ for the other parameters. The five different analyses for each subject, in fact, gave closely similar maximum $\log 1$ values $( \pm .02)$, even though in many cases the maxima occurred at substantially different parameter values (except for $\sigma_{D}$ ). The $\sigma_{\mathrm{D}}$ estimates were always stable and very close to the reciprocal of $\hat{\mathrm{d}}^{\prime}=\phi^{-1}(\hat{\mathrm{p}})-\phi^{-1}(\hat{\mathrm{q}})$. This is, of course, quite expected, given Equation 20 and the fairly weak first-order sequential effects in this data.

To compare $\log 1$ across GDM, RRM, MRM, a Subjects by Discriminability by Models analysis of variance was used. The model effect was significant $(p<.01)$ overall and at the two discriminability levels separately. Using Tukey's q statistic to compare the models pairwise, GDM and RRM do not differ significantly, but GDM and RRM do better than MRM at both levels of discriminability $(p<.01)$. GDM does nonsignificantly better than RRM $(\mathrm{q}=2.83)$ in the $\mathrm{L}$ condition.

\section{ON THE USE OF ASYMPTOTIC RESULTS: SOME SIMULATIONS}

This section considers the validity of applying Norman's theorem and the time series results to trials $n_{1}+1, n_{1}+2, \ldots, n_{1}+n_{2}$, earlier trials being discarded. At the outset, rate of convergence must be assumed to depend on the parameters $d, c_{0}, d_{i j}$, $\mathrm{i}, \mathrm{j}=1,2, \mathrm{n}_{1}, \mathrm{n}_{2}$. Since the criterion certainly cannot move further than $\left(n_{1}+n_{2}\right)^{*} \max \left(\left|\delta_{i j}\right|\right)$ from $c_{0}$, there is no doubt that we can find parameter combinations for which the fit of the asymptotic distributions is arbitrarily hopeless. What we need to know is over what regions of the parameter space the fit is satisfactory. In view of the rather substantial computing time involved, all that is achieved here is an investigation of some selected cases. 
The simulations were run on a DEC10 using a Fortran program written by the author. Each parameter combination was simulated for 1,000 sets of $n_{1}+n_{2}$ trials, except for $n_{2} \geqslant 200$, when 800 sets were run; execution time was of the order of $30 \mathrm{~min}$ to $3 \mathrm{~h}$, depending on $\mathrm{n}_{1}, \mathrm{n}_{2}$. The MacLaren-Marsaglia algorithm (Knuth, 1969) was used to generate uniform random numbers, by which stimulus events were determined. Random normal deviates representing the $f_{i}(x)$ were derived from the uniform random numbers using the polar coordinates method (Knuth, 1969) in order to determine the response events. The random number generator was initialized differently for each parameter combination. The statistics being studied were computed on the last $n_{2}$ of each set of trials, and their cumulative distributions were built up over the $1,000(800)$ sets of trials.

Two models only were investigated: DMM and $\mathrm{DMM} / \mathrm{NF}$. In both cases, it was assumed that $f_{1}(x)=f_{2}(x+d) \sim N[0,1]$. To investigate how convergence depends on $n_{2}$ when $n_{1}$ is large enough for the stationary distribution of $c_{n}$ to have been established, some runs set $c_{0}=\bar{c}$, where $\gamma \Phi(d-\bar{c})$ $+(1-\gamma) \Phi(-\overline{\mathrm{c}})=\gamma$. Thus, a criterion at $\overline{\mathrm{c}}$ gives $\mathrm{p}\left(\mathrm{r}_{2}\right)=\gamma$. For these runs, $\mathrm{n}_{1}=0, \mathrm{n}_{2}=100$. In the other runs, $c_{0}$ was set equal to $d / 2$; this is not, strictly speaking, a worst case, but it is perhaps a worst plausible case, the presumption being that subjects do not in practice start off biased against the more frequent stimulus, or, at the other extreme, from a position which gives gross overmatching. For these runs, $\left(n_{1}, n_{2}\right)$ took the values $(0,100)$, $(50,100),(100,100),(200,100),(300,100),(200,200)$. Only a brief summary of the results is given here.

\section{DMM, $\mathrm{c}_{0}=\overline{\mathbf{c}}$}

The cases investigated were all combinations of $\mathrm{d}=4,1.6 / / \delta=.035, .1, .35 / / \gamma=.7, .9 . \mathrm{t}=$ $\sqrt{\mathrm{N}}\left[\mathrm{p}_{\mathrm{N}}\left(\mathrm{r}_{2}\right)-\gamma\right] / \sqrt{[\gamma(1-\gamma)]}$ was compared to the standard normal $\Phi(t)$ (Norman's theorem). The $99 \%$ Kolmogorov-Smirnov limits include $\Phi(t)$ everywhere at the tails $[\Phi(t)=.01, .05, .1, .9, .95, .99]$, though not at the center in about half the cases, $t<0$ being too common. $t_{\mid \min }(0 \leqslant K \leqslant 10)$, which is just Equation 15 with $K$ in Equation 14 chosen so as to maximize $\hat{\sigma}^{2}$, is universally conservative at the tails, allowing for sampling variability.

\section{DMM, $c_{0}=d / 2$}

The same $d / / d / / y$ combinations as above were studied. For $\gamma=.7, n_{1} \geqslant 200$ seems sufficient to achieve a good fit for $t$ at the lower tail, with $t_{\mid \min }$ being safely conservative. Even for $n_{1}<200$, the fit at the tail may be quite tolerable provided $\delta$ is not too small, though the fit at the center is appalling. For $\gamma=.9 \mathrm{t}$ is slower to converge, but by $\mathrm{n}_{1}=200$ $t_{\mid \min }$ becomes conservative at the tail except for the smallest $\delta$. Note that $\chi_{\min }^{2}$, or a two-tailed test on $t_{|\min |}$, is more conservative than these one-tailed values might suggest because of the (often grossly) truncated upper tail.

\section{DMM $/ \mathbf{N F}, \mathrm{c}_{0}=\overline{\mathbf{c}}$}

The cases studied were all combinations of $\mathrm{d}=$ $.4,1.6 / /-\delta_{1}=.007, .014, .035, .07, .014, .35$ for $\gamma=.7$, and all combinations of $d=.4,1.6 / /-\delta_{1}=$ $.009, .018, .045, .09, .18, .36$ for $\gamma=.9 . t_{|\min |}$ is grossly conservative at the tails in all cases.

\section{$\mathrm{DMM} / \mathrm{NF}, \mathrm{c}_{\mathrm{o}}=\mathrm{d} / \mathbf{2}$}

The same $d / / \delta / / \gamma$ combinations as above were studied except that the smallest two $\delta_{1}$ cases were omitted. $t_{|\min |}$ is conservative at the lower tail, universally for $n_{1} \geqslant 200$, and often for smaller $n_{1}$.

\section{Summary}

(1) Provided $c_{o}$ is close to $\bar{c}$, neither $t$ nor $t_{|\min |}$ is likely to be seriously misleading.

(2) In other cases, fit is often good at the tails while bad at the center. This suggests that the number of significant $t, t_{\mid \min }, \chi^{2}$, or $\chi_{\min }^{2}$ values can in general be taken more seriously than, for example, $\Sigma \chi^{2}$, over subjects.

(3) At the tails, the $t_{\mid \min } \mid$ statistic is almost universally conservative among the cases studied provided $n_{1} \geqslant 200$, even given $c_{0}=d / 2$.

(4) It is, of course, possible to create arbitrarily poor fit by assuming $c_{0}$ sufficiently distant from $\bar{c}$ and the $\delta$ sufficiently small; and to make the situation quite hopeless, we can assume substantial interblock criterion shift so that $n_{1}$ can never be large. Fortunately, should such a depressing combination occur in practice, it ought to be detectable as a trend in $\hat{p}\left(r_{2}\right)$ over trials; this is always worth testing for whenever these statistics are applied.'

\section{OVERALL CONCLUSIONS}

The main conclusions from Dusoir (1974) and the data reported here are as follows:

(1) In none of the tasks studied have subjects universally matched $p\left(r_{2}\right)$ to $\gamma$, undermatched, overmatched, or kept $p\left(r_{2}\right)$ constant across discriminability. To save ALMs, in the no-feedback case, we must allow different models to fit different subjects; in the feedback case, we can either allow different models to fit different subjects or else assume the general deterministic or probabilistic model for all subjects. These possibilities are not testable by the methods used here.

(2) The general deterministic model did nonsignificantly better than the ad hoc response runs model with respect to $\log 1$ for the amplitude recognition task with feedback, but both models did substantially better than the memory recognition model. 
The simulation results back up the free use of asymptotic $\mathrm{p}_{\mathrm{N}}\left(\mathrm{r}_{2}\right)$ theory. Throughout the experiments, results have often been significant at an individual subject level, so that the poor fit of the asymptotic results at the center is not a problem. And we can rule out extreme $\left(c_{0}-\bar{c}\right)$ along with small $\delta$ by the entirely nonsignificant trend tests for crude nonstationarity and by the maximum likelihood estimates, which suggest neither large $\left(c_{0}-\bar{c}\right)$ nor small $\delta$, at least for the feedback case.

Of course, since the simulations investigate only two models, it is unclear whether some of the other ALMs might be defended by rejecting the application of the asymptotic theory. However, this seems an unfortunate move to have to make; the larger the variance of the statistics in question, the less ALMs explain about signal detection and recognition data. We can, in any case, cut through statistical uncertainties of this kind by appealing to detailed individual subject isobias curves; such will be reported separately.

\section{REFERENCES}

Anderson, T. W. The statistical analysis of time series. New York: Wiley, 1971.

Dorfman, D. D. The likelihood function of additive learning models: Sufficient conditions for log-concavity and uniqueness of maximum. Journal of Mathematical Psychology, 1973, 10, 73-85.

Dorfman, D. D., \& Biderman, M. A learning model for a continuum of sensory states. Journal of Mathematical Psychology, $1971,8,264-284$

Dorfman, D. D., Saslow, C. F., \& Simpson, J. C. Learning models for a continuum of sensory states reexamined. Journal of Mathematical Psychology, 1975, 12, 178-211.

Dusorr, A. E. Thomas \& Legge's matching hypothesis for detection and recognition tasks: Two tests. Perception \& Psychophysics, 1974, 16, 466-470.

Dusoir, A. E. Treatments of bias in detection and recognition models: A review. Perception \& Psychophysics, 1975, 17, 167-178.

Feller, W. An introduction to probability theory and its applications (Vol. 2). New York: Wiley, 1971.

Fletcher, R., \& Powell, M. J. D. A rapidly convergent descent method for minimization. Computing Journal, 1963, 6, 163-168.
HALLER, R. W. The role of information feedback in signal recognition. Unpublished doctoral dissertation, Stanford University, 1969.

KAC, M. A note on learning signal detection. IRE Transactions on Information Theory, 1962, IT-8, 126-128.

KENDALL, M. G. Rank correlation methods. London: London: Griffin, 1970.

Kendali, M. G. \& Stuant, A. The advanced theory of statistics (Vol. 2). London: Griffin, 1973.

KNUTH, D. E. The art of computer programming. (Vol. 2). Reading, Mass,: Addison-Wesley, 1969.

Kubovy, M., \& Healy, A. F. The decision rule in probabilistic categorization: What it is and how it is learned. Journal of Experimental Psychology: General, 1977, 106, 427-446.

Mood, A. M., \& Graybill, F. A. Introduction to the theory of statistics. New York: McGraw-Hill, 1963.

Norman, M. F. Statistical inference with dependent observations: Extensions of classical procedures. Journal of Mathematical Psychology, 1971, 8, 444-451.

Norman, M. F. Markov processes and learning models. New York: Academic Press, 1972.

Norman, M. F. Markovian learning processes. SIAM Review, 1974, 16, 143-162.

Polak, E. Computational methods in optimization: $A$ unified approach. New York: Academic Press, 1971.

Shenton, A. H. Inequalities for the normal integral, including a new continued fraction. Biometrika, 1954, 41, 177.

Tanner, T. A., Haller, R. W., \& Atrinson, R. C. Signal recognition as influenced by presentation schedules. Perception \& Psychophysics, 1967, 2, 349-358.

Tanner, T. A., Rauk, J. A., \& Atrinson, R. C. Signal recognition as influenced by information feedback. Journal of Mathematical Psychology, 1970, 7, 259-274.

Tном As, E. A. C. On a class of additive learning models: Errorcorrecting and probability matching. Journal of Mathematical Psychology, 1973, 10, 241-264.

Thomas, E. A. C. Criterion adjustment and probability matching. Perception \& Psychophysics, 1975, 18, 158-162.

Thomas, E. A. C. \& Legge, D. Probability matching as a basis for detection and recognition decisions. Psychological Review, $1970,77,65-72$.

\section{NOTE}

1. Detailed summaries of the simulation results are available from the author.

(Received for publication April 17, 1979; revision accepted November 3, 1979.) 